Supplement of J. Micropalaeontol., 37, 249-256, 2018

https://doi.org/10.5194/jm-37-249-2018-supplement

(C) Author(s) 2018. This work is distributed under

the Creative Commons Attribution 4.0 License.

(c) (1)

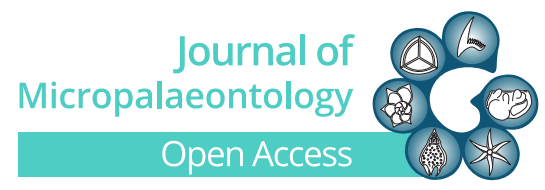

Supplement of

\title{
Modified cleaning method for biomineralized components
}

Hideto Tsutsui and Richard W. Jordan

Correspondence to: Hideto Tsutsui (blacksand@mail.goo.ne.jp)

The copyright of individual parts of the supplement might differ from the CC BY 4.0 License. 

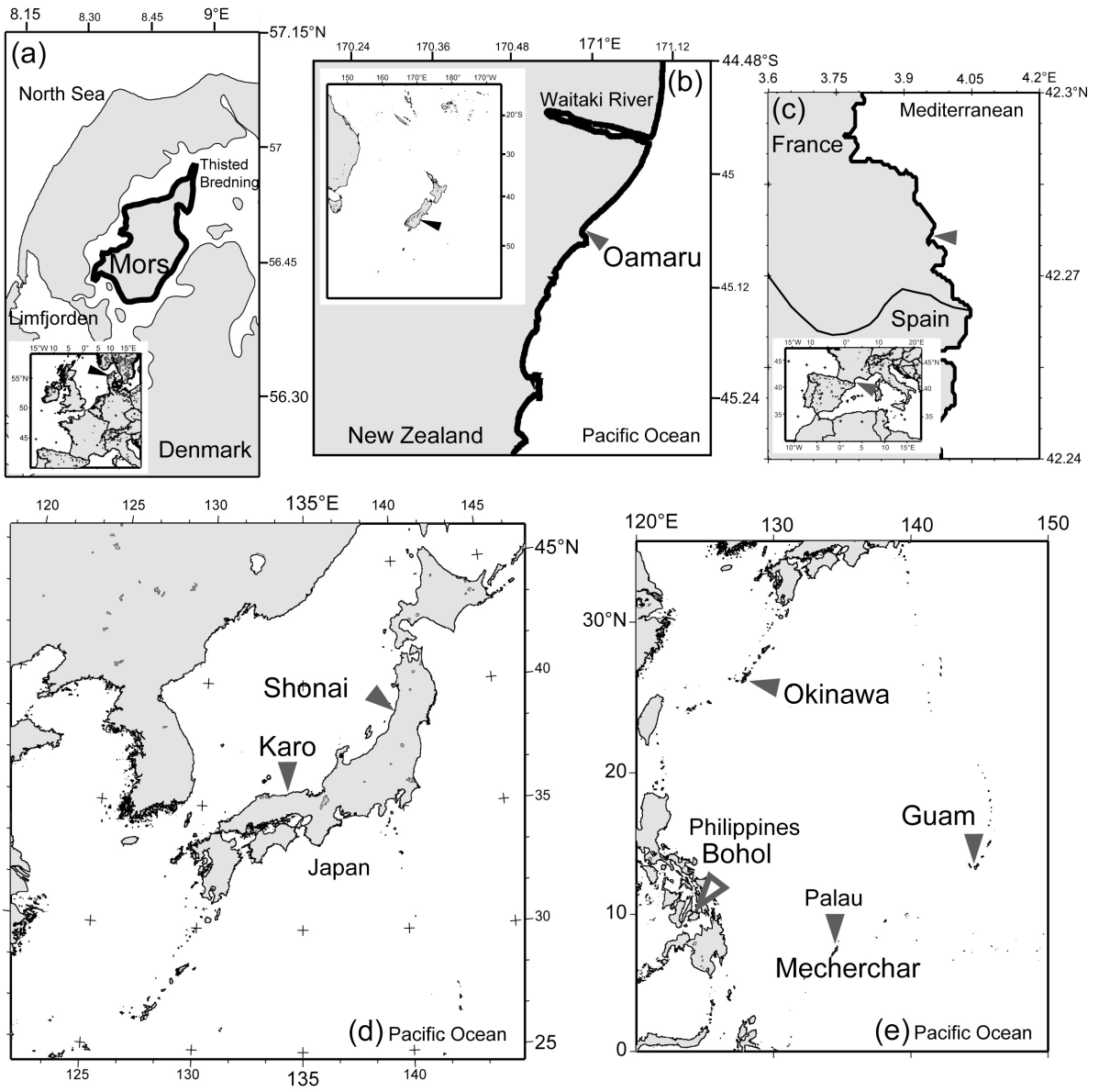

Fig. S1. Maps showing the locations of the diatom-bearing samples from (a) Mors Island in

Denmark and (b) Oamaru in New Zealand; the holothurian sampling points in (c) France and (e)

5 Okinawa, Bohol, and Guam; (d) the approximate locations where the sailfin sandfish were caught

6 off the Shonai and Karo coasts in Japan; and (e) the fossil foraminifer sampling point in Mecherchar

7 Jellyfish Lake, Mecherchar Island, Palau. All maps are based on Collaborative Research Center

8 (SFB) 574, Volatiles and Fluids in Subduction Zones (http://sfb574.geomar.de/gmt-maps.html). 

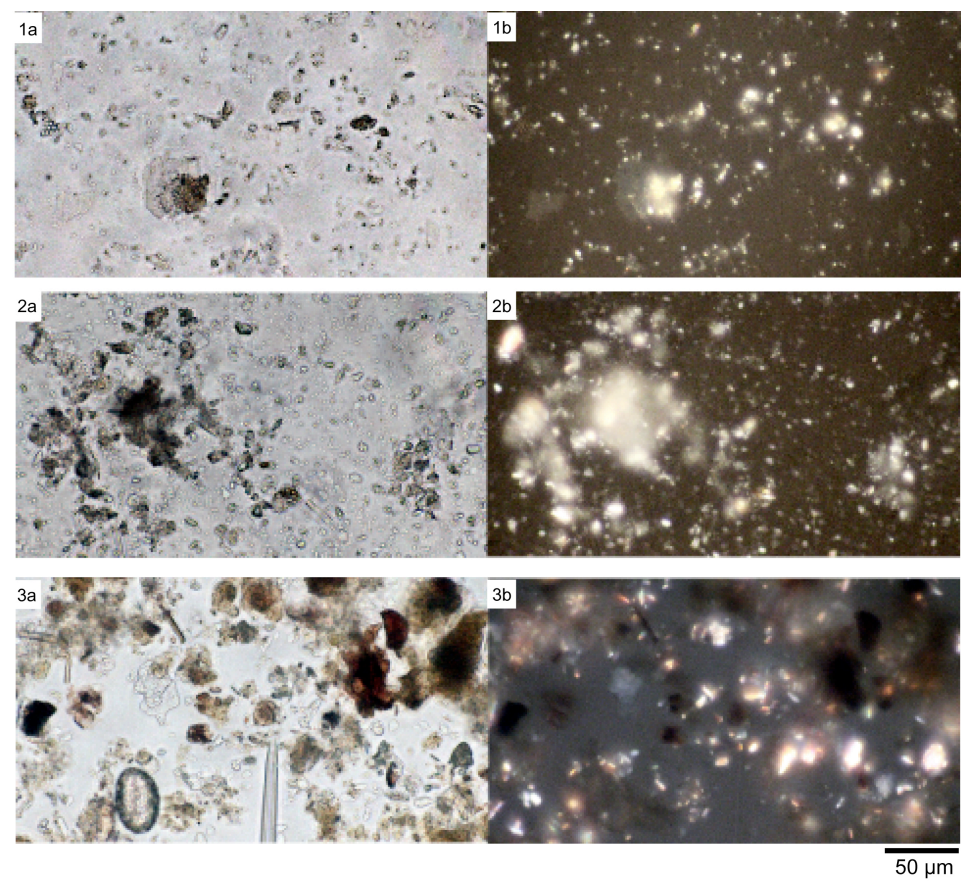

Plate S1. Photomicrographs of the water mounts of the untreated material. fig. 1a-b. Mors diatomite.

11 Many coccoliths were observed in cross nicols. fig. 2a-b. Oamaru diatom-bearing sediment. fig. 3a-

12 b. JFL sediments. figs 1a, $2 a$ and $3 a$ were taken in open nicols, while figs $1 b$, $2 b$, and $3 b$ were taken 13 in crossed nicols. 

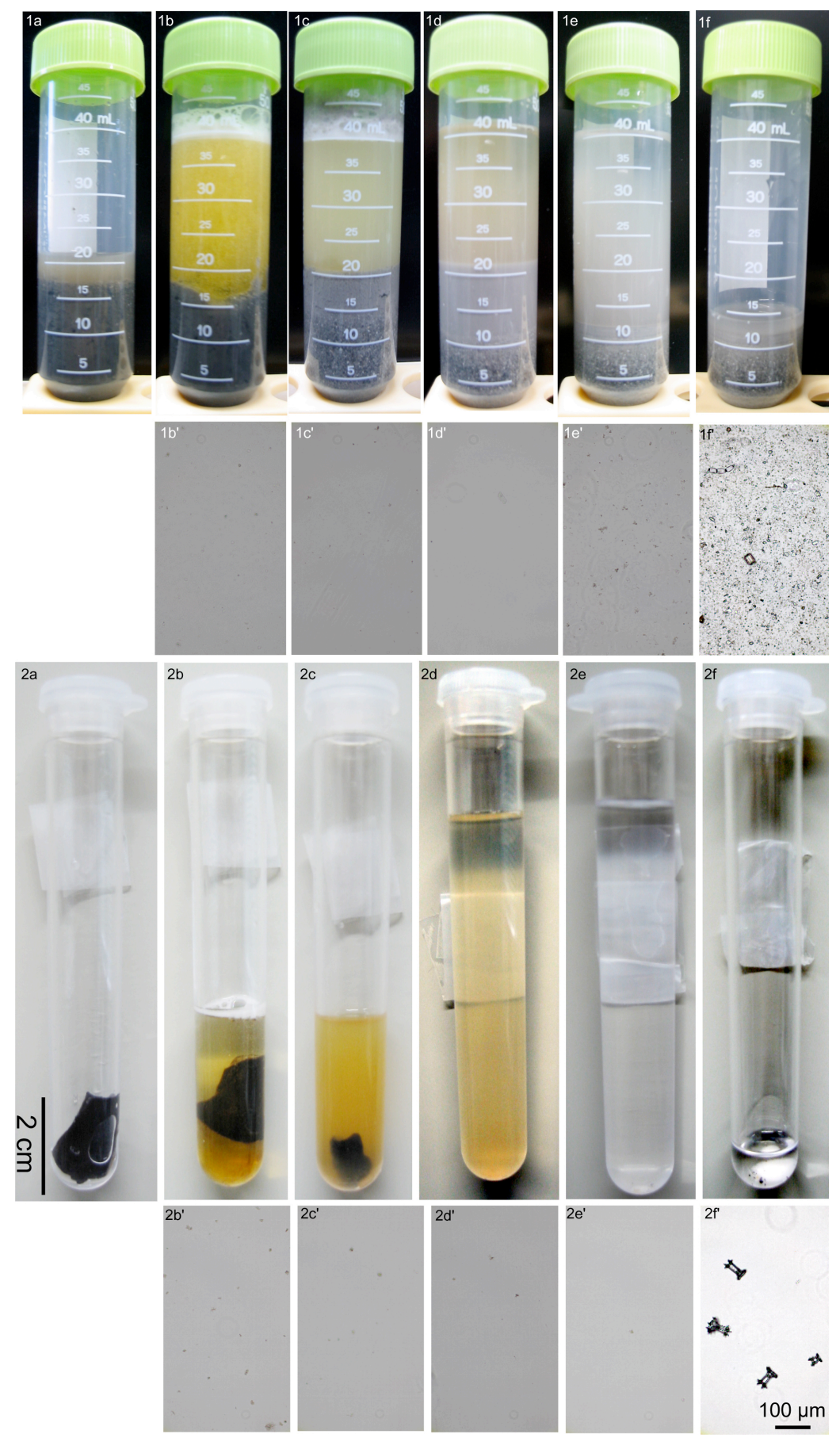

Plate S2. Step-by step process, showing the supernatant in the centrifuge tubes of the East China Sea sediment (figs. 1a-1f), sampled on $2^{\text {nd }}$ August 2016 during the NS16-442 cruise of the T/S Nagasaki Maru, and of a specimen of Holothuria leucospilota (holothuria, sea cucumber), collected from Taketomi Island, Okinawa, Japan on $20^{\text {th }}$ June 2015 (figs. 2a-2f). Photomicrographs of the discarded supernatant are shown for the sediment (figs. 1b'-1e') and for the holothurian (figs. 2b'-2e'). Also shown are photomicrographs of final pellet containing fossil diatoms in the sediment (fig. 1f') and ossicles of the holothurian (fig. 2f'). 